\title{
Neuroimaging in Multiple Sclerosis: Neurotherapeutic Implications
}

\author{
Nancy L. Sicotte \\ Multiple Sclerosis Research and Treatment Program, Division of Brain Mapping, Department of Neurology, David Geffen School of \\ Medicine at UCLA, 710 Westwood Blvd, Rm 4-238, Los Angeles, California 90095
}

\begin{abstract}
Summary: Imaging techniques, in particular magnetic resonance imaging (MRI), play an important role in the diagnosis and management of multiple sclerosis (MS) and related demyelinating diseases. Findings on MRI studies of the brain and spinal cord are critical for MS diagnosis, are used to monitor treatment response and may aid in predicting disease progression in individual patients. In addition, results of imaging studies serve as essential biomarkers in clinical trials of putative MS therapies and have led to important insights into disease pathophysiology. Although they are useful tools and provide in vivo measures of disease-related activity, there are some important limitations of MRI findings in MS, including the non-specific nature of detectable white matter changes, the poor correlation with clinical disability, the limited sensitivity
\end{abstract}

and ability of standard measures of gadolinium enhancing lesions and T2 lesions to predict future clinical course, and the lack of validated biomarkers of long term outcomes. Advancements that hold promise for the future include new techniques that are sensitive to diffuse changes, the increased use of higher field scanners, measures that capture disease related changes in gray matter, and the use of combined structural and functional imaging approaches to assess the complex and evolving disease process that occurs during the course of MS. Key Words: Multiple sclerosis, magnetic resonance imaging, neurodegeneration, cognitive impairment, diffusion tensor imaging, functional magnetic resonance imaging.

\section{INTRODUCTION}

Multiple sclerosis (MS) is an inflammatory autoimmune disorder of the central nervous system that is frequently associated with the development of significant disability. There are approximately 400,000 cases of MS in the USA, or $0.1 \%$ of the general population. The age of onset is in young adulthood (ages 20-40), and women are affected more commonly than men [1]. The female:male ratio of 2:1 is usually cited, but newer studies suggest an increasing female preponderance, ranging from $4: 1$ to $7: 1[2,3]$. The reason for this greater skewing by sex is not clear, although several intriguing theories have been proposed $[4,5]$. Acute attacks of neurological impairment (relapses) followed by variable degrees of improvement (remission) characterizes relapsing remitting MS (RRMS), representing $85 \%$ of newly diagnosed cases. The majority of RRMS patients will eventually transition to a disease stage in which relapses are less common or even absent, and a slowly

Electronic supplementary material The online version of this article (doi:10.1007/s13311-010-0008-y) contains supplementary material, which is available to authorized users.

Address correspondence and reprint requests to: Nancy L. Sicotte M.D., FAAN, Multiple Sclerosis Research and Treatment Program, Division of Brain Mapping, Department of Neurology, David Geffen School of Medicine at UCLA, 710 Westwood Blvd, Rm 4-238, Los Angeles, CA 90095. E-mail: nsicotte@ucla.edu. progressive disability ensues, classified as secondary progressive MS (SPMS). Another form is primary progressive MS, which is associated with a slowly progressive myelopathy, an older age at onset, and equal distribution among men and women; this form accounts for $10 \%$ of new MS diagnoses. Progressive-relapsing MS in which relapses occur after an initially progressive form accounts for the remaining 5\% of cases [6]. In addition to these classical MS subtypes, there are several MS variants, including neuromyelitis optica and acute disseminated encephalomyelitis [7].

\section{DIAGNOSIS}

The specific diagnostic criteria for MS have undergone considerable modification in the past few decades with recent changes incorporating findings from magnetic resonance imaging (MRI) to a greater extent. However, it is important to recognize that the principles that underscore MS diagnosis have not changed; namely, the need to establish dissemination in time and space after ruling out other MS mimics [8] and other disorders that can have associated MRI abnormalities [9]. In the past, clinical events and findings on examination were required to establish dissemination in both time and space [10]. Under the new McDonald criteria, findings 
on MR images can fulfill both requirements [11]. Classic examples of first demyelinating events include optic neuritis or transverse myelitis. When a patient presents initially with one of these clinically isolated syndromes (CIS) or other suggestive symptoms, findings on MR images are critical in establishing the likelihood that this represents the first clinical episode of MS. Standard MRI sequences, such as double echo proton density/T2weighted or, especially, fluid-attenuated inversion recovery (FLAIR) imaging, are used to detect areas of high signal in the white matter that are the hallmark of inflammatory demyelination. New white matter lesions will frequently show enhancement with the uptake of gadolinium (Gd)-based contrast agents. The presence of $\mathrm{Gd}+$ lesions is more sensitive and specific for MS and is a useful measure of acute inflammation, with lesions typically showing enhancement for $6-8$ weeks. The appearance of 2 or more white matter lesions at the time of a clinically isolated event is associated with a high risk of developing clinically definite MS [12]. Key characteristics of white matter lesions that are associated with MS were originally identified by Barkhof et al. [13] and subsequently modified [14]; these are helpful in differentiating likely demyelinating lesions from non-specific changes in white matter. See Table 1 for the Barkhof MRI criteria.

\section{MRI criteria for diagnosis: A moving target}

The original McDonald diagnostic criteria for MS incorporated the modified Barkhof criteria to establish dissemination in space and a somewhat complicated algorithm to establish dissemination in time using findings on serial MR images [11]. Modifications in 2005 reflected the important role that spinal cord imaging plays in the diagnosis of MS and simplified the establishment of dissemination in time [15]. Most recently, the MAGNIMS group has proposed new guidelines that would allow a diagnosis of MS in a CIS patient with a single MRI scan that demonstrated typical white matter lesions meeting Barkhof criteria (dissemination in space) and consisting of a mixture of both enhancing and nonenhancing lesions (dissemination in time) [16].

Individuals with characteristic MRI findings in the absence of clinical symptoms and with an entirely normal neurological examination have been described as having a "radiologically isolated syndrome" or preclinical MS.

Table 1. Barkhof Magnetic Resonance Imaging Criteria

3 of 4 of the following are required:

1. Gadolinium-enhanced lesion or the presence of $>9 \mathrm{~T} 2$ lesions

2. One infratentorial lesion

3. One juxtacortical lesion

4. 3 periventricular lesions
Recent longitudinal cohort studies suggest that about onethird of such patients will convert to CIS over the course of 2 years $[17,18]$ and that the presence of spinal cord lesions is associated with a faster clinical conversion [19].

\section{MRI as a surrogate marker}

Acute inflammatory activity. Initial studies of MS using serial MRI scans revealed the presence of new inflammatory activity occurring at a rate seven- to tenfold greater than the clinical events $[20,21]$. The sensitivity of MRI to detect ongoing disease activity in the absence of less frequent and sometimes hard to define clinical worsening has made it an attractive readout for assessing treatment effects in clinical trials [20]. Subsequent studies have convincingly demonstrated that the presence of active inflammation, as detected with $\mathrm{Gd}+$ lesions, is associated with a higher likelihood of relapse activity [22]. As a readout of acute inflammation and short-term clinical activity, Gd + enhancing lesion numbers and volumes are among the most robust MRI biomarkers of MS [23, 24] and short-term disability progression [25].

Cumulative disease burden. While $\mathrm{Gd}+$ lesions reflect transient inflammatory events, changes in T2/ FLAIR lesion numbers and volumes are measures of cumulative lesion formation and can be used in lieu of $\mathrm{Gd}+$ lesion counts [26]. The relationship to future disability is only modest [27], and other measures that reflect global and gray matter changes have been shown to be better predictors of long-term outcomes [28, 29]. Despite this evidence, MRI outcomes for exploratory Phase II studies of MS therapies continue to use Gd + lesions and T2 volumes. While clinical metrics (decrease in relapse rate or slowing of disability progression) are the primary outcome measures in definitive Phase III clinical trials, changes in lesion burden detected by MRI remain important secondary outcome measures.

\section{TREATMENT EFFECTS}

All currently available disease-modifying therapies for MS have been shown to have significant effects on MRI measures of white matter inflammation. The original studies with interferon- $\beta$ showed a dramatic reduction in Gd + activity [30] and subsequently a more modest decrease in relapse rate [31]. Treatment with the firstgeneration injectable therapies, such as interferon beta- $1 \mathrm{~b}$ (Betaseron; Bayer Healthcare Pharmaceuticals, Wayne, $\mathrm{JF}$ ), and interferon beta-1a [Avonex (Biogen Idec, Weston, MA); Rebif (Merck Serono, Geneva, Switzerland)] and glatiramer acetatate (Copaxone; Teva Pharmaceuticals, Petah Tikva, Israel), leads to variable decreases in $\mathrm{Gd}+$ activity and the number and volume of T2 lesions [31-37] and, on average, a $30 \%$ reduction in relapses $[7,31,36,38$, 
39]. However, a dose/response relationship is evident with high doses of interferon- $\beta$ associated with more pronounced reductions in MR disease activity and relapses [36, 40-42].

Newer therapies have also shown pronounced effects on inflammatory activity and significant decreases in relapse rates. Natalizumab (Tysabri; Biogen Idec and Élan, Roscommon, Ireland) was tested first in combination with interferon beta-1a [43], which may have increased the risk for developing progressive multifocal leukoencephalopathy. Subsequent Phase III trials showed what appeared to be more prominent treatment benefits of natalizumab versus the first-generation injectable therapies. In both the SENTINAL [44] and AFFIRM [45] studies, MRI activity and relapse rates were suppressed significantly. However, the patient cohorts tested were diagnosed using McDonald criteria, were younger, and had overall lower disease activity which may have led to an overestimation of the treatment response [46], especially if the relative risk reduction is reported instead of absolute risk reduction [47].

The limitations of relying solely on markers of inflammation came into focus when these therapies were used to treat patients with progressive forms of MS. The European trial of interferon beta- $1 \mathrm{~b}$ in SPMS found benefits in markers of inflammation and disease progression [48, 49]. However, a North American trial failed to find a similar effect [50]. Subsequent analysis of the two patient cohorts revealed that the benefits of interferon therapy on disease progression was limited to the group with higher levels of $\mathrm{Gd}+$ activity and continued relapses [51]. The results from a series of studies with alemtuzamb (Campath; Genzyme, Cambridge, MA) provided more evidence for the complex role that inflammation plays in causing future disability. When used in progressive patients, Campath eliminates all traces of inflammatory lesion activity, but it has no impact on disability progression. However, treatment in early RRMS appears to stabilize the disease, suggesting that early inflammatory events lead to future neurodegenerative changes and worsening neurological function [52, 53]. Results from these therapeutic trials provide further evidence for the early treatment of MS with potent therapies.

\section{NEURODEGENERATION}

TI black holes. T2/FLAIR lesion volumes are only modestly correlated with concomitant disability measures due to several factors, including limitations in commonly used disability measures, the lack of pathological specificity of MR signal changes, and functional compensation that limits the clinical expression of accumulated disease burden [54]. Several other measures have been explored to overcome these limitations. T1 "black holes" are areas of hypointensity detected on T1weighted scans; they represent a subset of T2 lesions with greater degrees of tissue destruction [55] and are more highly correlated with disability measures [56]. Serial studies demonstrate that there is considerable evolution of these initially hypointense lesions over many months and that their development is related to the intensity and persistence of initial inflammatory activity [57, 58] (FIG. 1). The ratio of T1 black hole volume to overall $\mathrm{T} 2$ volumes has been incorporated in composite MR scales as a measure of disease severity that predicts future disability progression [59]. The ability to limit the development of $\mathrm{T} 1$ black holes has been suggested as a surrogate marker for reparative or neuroprotective therapeutic effects [60]. Modest effects have been reported in short-term studies of Copaxone [61], although the methodology used generated some controversy [62]. Trials of interferon beta- $1 \mathrm{~b}$ in SPMS showed a reduction in $\mathrm{T} 1$ hole formation, although this may have been due to an overall decrease in new lesion activity [63]. In RRMS, interferon beta-1b decreased the accumulation of $\mathrm{T} 1$ black holes but did not decrease their persistence [64]. A similar benefit was reported with interferon beta-1a SQ [65]. The BECOME study provided a head-to-head comparison of treatment effects on T1 black hole accumulation over 2 years and found a trend towards a lower conversion rate of acute black holes $(\mathrm{ABH})$ to chronic black holes $(\mathrm{CBH})$ with interferon beta-1b compared to copolymer-1 [66]. Notably, while the majority of the newly enhancing lesions were associated with $\mathrm{ABH}(62.7 \%$ overall), only a small proportion of $\mathrm{Gd}+$ lesions (12\%) became $\mathrm{CBH}$ when assessed over at least a 1-year period. These relatively low conversion rates make designing treatment trials powered to detect effects on the conversion of $\mathrm{ABH}$ to $\mathrm{CBH}$ challenging [67].

Atrophy. MRI-derived measures of atrophy have emerged as the most frequently used metric to capture the neurodegenerative process in MS, while Gd + activity and T2 lesion volume accumulation are measures of the "inflammatory" component of the disease. In practice, the distinction is not so neat, as inflammatory activity and brain volume measures are intertwined, making assessing treatment effects nuanced. Initial studies using global brain volume measures convincingly demonstrated that atrophy could be detected in RRMS [68] and could be measured accurately and reproducibly using automated techniques, such as the brain parenchymal fraction. In turn, these automated measures were used to monitor treatment effects on brain atrophy rates [69]. However, it has became clear that global brain volume measures are sensitive to changes in brain water content, which in turn fluctuate with disease activity and fluid status. For example, therapies with potent anti- 


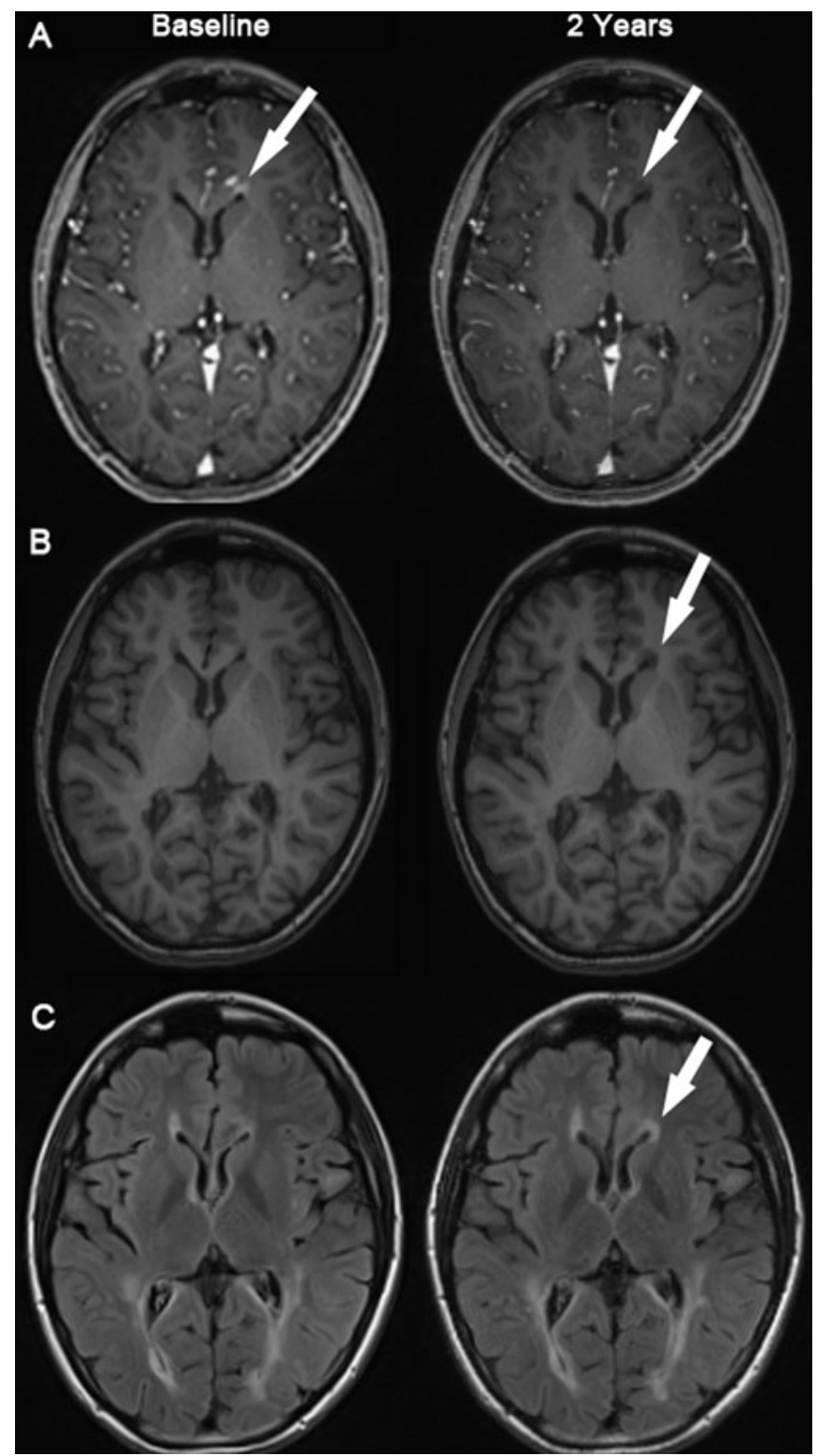

FIG. 1. Serial cerebral magnetic resonance (MR) images demonstrate lesion evolution in relapsing remitting multiple sclerosis (MS). Conventional MR imaging is used to capture inflammatory disease activity in MS, including gadolinium (Gd)-enhanced T1 scans (A), T1weighted scans without contrast (B), and fluid-attenuated inversion recovery (FLAIR) scans (C)). A newly enhancing lesion (white arrow) is seen at baseline (A, left column) which leads to the development of a chronic black hole at 2 years ( $\mathrm{A}, \mathrm{B}$, right column, white arrow) and increased area of FLAIR abnormality (C), right column, arrow). Note the increase in overall FLAIR white matter lesion volumes as well as the ventricular enlargement occurring over a 2-year period in relapsing remitting MS (RRMS) with minimal disability progression, as measured by the Expanded Disability Status Scale (EDSS; 1.5 to $>2.0$ ). (High resolution version of this image is available in the electronic supplementary material.)

inflammatory effects produce a more rapid, but transient rate of brain volume loss - the so-called pseudoatrophy effect — but may have differing effects in slowing brain volume loss with longer term treatment [70].

A recent study found that the rate of global brain atrophy varies across patients with MS; however, when baseline atrophy is accounted for, the rate is similar across the disease spectrum [71]. Long-term studies have validated the relationship between global brain atrophy and disability, as measured by the Expanded Disability Status Scale
(EDSS) and the MS functional composite score (MSFC) [72], and also indicated that brain atrophy rate during the RR phase was a significant predictor of subsequent disability [53], suggesting that atrophy is clinically relevant.

Interferon preparations have been shown to slow the rate of brain atrophy in the second year of treatment in RRMS [73-75] but not in SPMS [76]. An initial analysis of a study using a less sensitive central brain slice methodology failed to find an effect of copolymer-1 in slowing the rate of brain atrophy [77], but a subsequent 
re-analysis using the automated SEINA approach did demonstrate a benefit of treatment [78].

Measures of specific tissue types reveal that there are distinct atrophy rates in gray matter versus white matter regions in the brain, and that while white matter regions show a steady decrease, gray matter atrophy accelerates over time and is a more sensitive predictor of future disability $[28,29]$. There is emerging evidence that the appearance of white matter lesions is linked to subsequent cortical gray matter changes, although the specific location of the lesions may influence the degree of gray matter change detected [79]. This fits with the treatment effects on whole brain atrophy reported above, which found a slowing of brain atrophy after several months of treatment, thus reflecting the delayed impact of suppressing white matter inflammatory changes.

Only a few studies have specifically assessed treatment effects on gray matter atrophy, although measuring neuroprotective and remyelination effects is of great importance for future MS therapeutics [60]. One study suggests a benefit of interferon beta-1a (Avonex) in slowing the rate of gray matter atrophy, detectable at 2 and 3 years after initiating treatment [80]. Another recent study found that gray matter loss was detected in patients treated with interferon- $\beta$ but not in untreated or Copaxone-treated patients assessed over a 2-year period using a voxel-based morphometry approach [81]. However, interpretation of the latter study is limited by the small sample size and the lack of randomization.

Regional gray matter changes. There is increasing evidence that gray matter regions are also impacted in MS and that some gray matter regions are especially susceptible. For example, newer techniques at higher fields as well as detailed pathological analyses have revealed widespread demyelination in the cerebral cortex
[82-85]. The impact of disease modifying agents (DMAs) on cortical plaques has not been studied in detail to date. and such studies will be complicated by the lack of sensitivity of current imaging techniques in detecting the majority of cortical plaques [86]. In addition to the cortical rim, deep gray matter structures are also impacted in MS, with the thalamus showing early and significant atrophy associated with axonal and neuronal loss $[87,88]$. Thalamic atrophy has been linked with fatigue and cognitive impairment [89, 90], but the effect of DMAs on thalamic volume or function has not been assessed. The hippocampus is an archicortical gray matter structure that is impacted by MS and related to cognitive impairment [91]. Pathological studies show demyelination and neuronal loss throughout the hippocampal formation [92, 93]. Recent evidence suggests that there may be subregional susceptibility to distinct MS disease processes linked to depression and cognitive impairment in the hippocampus [94, 95]. Although changes in these distinct gray matter areas are well documented, few current studies are targeting MR outcome measures to assess specific treatment effects on these key brain areas.

\section{MEASURING THERAPEUTIC EFFICACY}

Although it is an important outcome measure for the assessment of new therapies, the use of MRI to monitor treatment response lacks consensus among practitioners $[59,96]$. It is difficult to define "breakthrough" disease, although most experienced clinicians seem to "know it when they see it". However, there is some evidence that in the setting of clinical events, the presence of new inflammatory activity detected on MR images should prompt a consideration to change therapy [97]. The

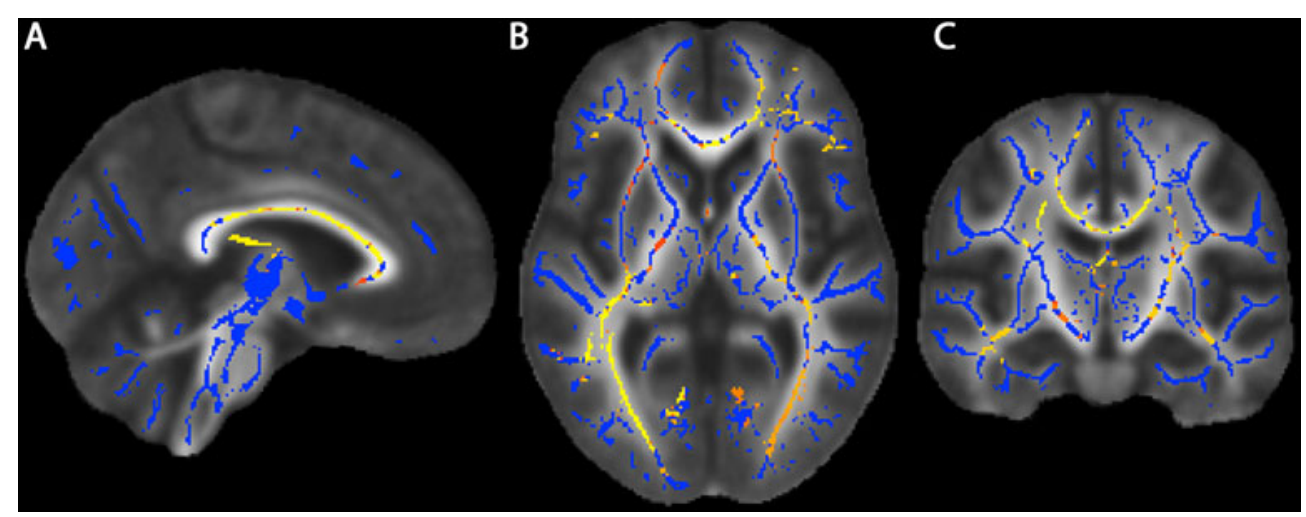

FIG. 2. Diffusion tensor imaging assessed with tract-based spatial statistics (TBSS) detects widespread white matter abnormalities in RRMS Statistical maps of a group comparison between healthy controls $(n=19)$ and RRMS patients $(n=29)$ based on fractional anisotropy $(\mathrm{fA})$ reveal widespread decreases in $f A$ in RRMS patients with a low disability (EDSS $<3)$. Shown are sagittal (A), axial (B), and coronal (C) views. The TBSS skeleton is overlaid onto a group atlas and color-coded to reveal regions with statistically significantly decreased fA RRMS compared to healthy controls. White matter disruption involves extensive regions of the corpus callosum, optic radiations and temporal lobe white matter. Future and current therapies should be assessed using this and other non-conventional techniques that can detect tissue disruptions beyond traditional white matter lesions. (High resolution version of this image is available in the electronic supplementary material.) 
search for relevant biomarkers continues, with a recent finding that baseline cytokine levels can predict the response to interferon treatment a promising advance [98], although other approaches, such as monitoring biological response markers, seem to be unhelpful in identifying non-responders [99].

\section{NEW APPROACHES}

Future clinical trials will incorporate newer techniques and use high-field-strength MRI scanners to better capture the diffuse disease effects discussed above that are currently not captured by inflammatory lesion counts. (FIG. 2). For example, MRI performed at high field $(\geq 3 \mathrm{~T})$ and specific sequences, such as double inversion recovery imaging, capture larger number of cortical lesions [100, 101]. Magnetization transfer imaging, which can be used to quantify intact myelin, has been proposed as a biomarker for remyelination [102]. Spectroscopy can be used to detect metabolites that reflect axonal/neuronal integrity and has been used as a measure of neuroprotective effects [103] and excitotoxicity [104]. Diffusion tensor imaging can be used to monitor tract-specific changes that may be more closely linked to clinical measures $[105,106]$ and may be particularly powerful when combined with functional measures, such as functional MRI [107]. T1/T2 relaxation is another quantitative approach that may provide a better metric for diffuse brain changes occurring beyond traditional white matter regions [108] and to quantify myelin content [109]. Quantification of brain iron levels is an area attracting intense interest [110]. Other more technically challenging approaches include molecular imaging [111] and sodium imaging [112]. In general, these latter two approaches have not been applied to multicenter treatment trials because of technical complexities and a lack of standardizations across sites and between different MR equipment manufacturers [113]. However, these limitations are not insurmountable, but they do require a consortium approach, as recent publications demonstrate [114].

\section{CONCLUSIONS}

Findings on conventional MRI scans have contributed significantly to the clinical care of persons with MS by allowing for early diagnosis and treatment. In addition, key pathophysiological insights have been gleaned from MRI data obtained in practice and in clinical trials. New challenges are to develop sensitive and more specific markers of disease effects beyond detectable white matter lesion areas. Newer therapies developed to slow neurodegeneration or promote remyelination will require the use of advanced multimodal MRI techniques that capture structural and functional changes. The adoption of these cutting edge techniques into multicenter trials will be technically challenging, but feasible in the near future.

Acknowledgements: Funding is from the National MS Society (RG3914, RG4176, RG3915-A-15) and the NIH/ NINDS (RO1 NS 051591).

\section{REFERENCES}

1. Noseworthy JH, Lucchinetti C, Rodriguez M, Weinshenker BG. Multiple sclerosis. N Engl J Med 2000;343:938-52.

2. Alonso A, Hernan MA. Temporal trends in the incidence of multiple sclerosis: a systematic review. Neurology 2008;71:129_ 35.

3. Taylor BV, Lucas RM, Dear K, et al. Latitudinal variation in incidence and type of first central nervous system demyelinating events. Mult Scler 2010;16:398-405.

4. Eikelenboom MJ, Killestein J, Kragt JJ, Uitdehaag BM, Polman $\mathrm{CH}$. Gender differences in multiple sclerosis: cytokines and vitamin D. J Neurol Sci 2009;286:40-2.

5. Tintore M, Arrambide G. Early onset multiple sclerosis: the role of gender. J Neurol Sci 2009;286:31-4.

6. Lublin FD, Reingold SC. Defining the clinical course of multiple sclerosis: results of an international survey. National Multiple Sclerosis Society (USA) Advisory Committee on Clinical Trials of New Agents in Multiple Sclerosis. Neurology 1996;46:907-11.

7. Wingerchuk DM, Lucchinetti CF. Comparative immunopathogenesis of acute disseminated encephalomyelitis, neuromyelitis optica, and multiple sclerosis. Curr Opin Neurol 2007;20:343-50.

8. Miller DH, Weinshenker BG, Filippi M, et al. Differential diagnosis of suspected multiple sclerosis: a consensus approach. Mult Scler 2008; 14:1157-74.

9. Charil A, Yousry TA, Rovaris M, et al. MRI and the diagnosis of multiple sclerosis: expanding the concept of "no better explanation". Lancet Neurol 2006;5:841-52.

10. Poser CM, Paty DW, Scheinberg L, et al. New diagnostic criteria for multiple sclerosis: guidelines for research protocols. Ann Neurol 1983;13:227-31.

11. McDonald WI, Compston A, Edan G, et al. Recommended diagnostic criteria for multiple sclerosis: guidelines from the International Panel on the diagnosis of multiple sclerosis. Ann Neurol 2001;50:121-7.

12. O'Riordan JI, Thompson AJ, Kingsley DP, et al. The prognostic value of brain MRI in clinically isolated syndromes of the CNS. A 10-year follow-up. Brain 1998;121:495-503

13. Barkhof F, Filippi M, Miller DH, et al. Comparison of MRI criteria at first presentation to predict conversion to clinically definite multiple sclerosis. Brain 1997;120:2059-69.

14. Tintore M, Rovira A, Brieva L, et al. Isolated demyelinating syndromes: comparison of CSF oligoclonal bands and different MR imaging criteria to predict conversion to CDMS. Mult Scler 2001;7:359-63.

15. Polman CH, Reingold SC, Edan G, et al. Diagnostic criteria for multiple sclerosis: 2005 revisions to the "McDonald Criteria". Ann Neurol 2005;58:840-6.

16. Montalban X, Tintore M, Swanton J, et al. MRI criteria for MS in patients with clinically isolated syndromes. Neurology 2010;74:427-34.

17. Lebrun C, Bensa C, Debouverie M, et al. Unexpected multiple sclerosis: follow-up of 30 patients with magnetic resonance imaging and clinical conversion profile. J Neurol Neurosurg Psychiatry 2008;79:195-8.

18. Okuda DT, Mowry EM, Beheshtian A, et al. Incidental MRI anomalies suggestive of multiple sclerosis. The radiologically isolated syndrome. Neurology 2009;72:800-5. 
19. Okuda DT, Crabtree E, Mowry EM, et al. Asymptomatic spinal cord lesions predict clinical progression in radiologically isolated syndrome (RIS) ubjects. Neurology 2010;74 (Suppl 2):A119.

20. Frank JA, Stone LA, Smith ME, Albert PS, Maloni H, McFarland HF. Serial contrast-enhanced magnetic resonance imaging in patients with early relapsing-remitting multiple sclerosis: implications for treatment trials. Ann Neurol 1994;36 (Suppl):S86-90.

21. Miller DH, Rudge P, Johnson G, et al. Serial gadolinium enhanced magnetic resonance imaging in multiple sclerosis. Brain 1988;111:927-39.

22. Kappos L, Moeri D, Radue EW, et al. Predictive value of gadolinium-enhanced magnetic resonance imaging for relapse rate and changes in disability or impairment in multiple sclerosis: a meta-analysis. Gadolinium MRI Meta-analysis Group. Lancet 1999;353:964-9.

23. Miller DH. Biomarkers and surrogate outcomes in neurodegenerative disease: lessons from $\backslash$ multiple sclerosis. NeuroRx 2004;1:284-94.

24. Sormani MP, Bonzano L, Roccatagliata L, Cutter GR, Mancardi GL, Bruzzi P. Magnetic resonance imaging as a potential surrogate for relapses in multiple sclerosis: a meta-analytic approach. Ann Neurol 2009;65:268-75

25. Sormani MP, Bonzano L, Roccatagliata L, Mancardi GL, Uccelli A, Bruzzi P. Surrogate endpoints for EDSS worsening in multiple sclerosis. A meta-analytic approach. Neurology 2010;75:302-9.

26. Zhao GJ, Koopmans RA, Li DK, Bedell L, Paty DW. Effect of interferon beta-1b in MS: assessment of annual accumulation of PD/T2 activity on MRI. UBC MS/MRI Analysis Group and the MS Study Group. Neurology 2000;54:200-6.

27. Fisniku LK, Brex PA, Altmann DR, et al. Disability and T2 MRI lesions: a 20-year follow-up of patients with relapse onset of multiple sclerosis. Brain 2008;131:808-17.

28. Fisher E, Lee JC, Nakamura K, Rudick RA. Gray matter atrophy in multiple sclerosis: a longitudinal study. Ann Neurol 2008;64:25565

29. Fisniku LK, Chard DT, Jackson JS, et al. Gray matter atrophy is related to long-term disability in multiple sclerosis. Ann Neurol 2008;64:247-54.

30. Stone LA, Frank JA, Albert PS, et al. The effect of interferon-beta on blood-brain barrier disruptions demonstrated by contrastenhanced magnetic resonance imaging in relapsing-remitting multiple sclerosis. Ann Neurol 1995;37:611-9.

31. Paty D, Li DK, Group UMMS. Interferon beta-1b is effective in relapsing-remitting multiple sclerosis. I. Clinical results of a multicenter, randomized, double- blind, placebo-controlled trial. The IFNB Multiple Sclerosis Study Group. Neurology 1993;43:655-61.

32. Paty DW, Li DK. Interferon beta-1b is effective in relapsingremitting multiple sclerosis. II. MRI analysis results of a multicenter, randomized, double-blind, placebo-controlled trial. UBC MS/MRI Study Group and the IFNB Multiple Sclerosis Study Group. Neurology 1993;43:662-7.

33. Simon JH, Jacobs LD, Campion M, et al. Magnetic resonance studies of intramuscular interferon beta-1a for relapsing multiple sclerosis. The Multiple Sclerosis Collaborative Research Group [see comments]. Ann Neurol 1998;43:79-87.

34. Li DK, Paty DW. Magnetic resonance imaging results of the PRISMS trial: a randomized, double-blind, placebo-controlled study of interferon-betala in relapsing-remitting multiple sclerosis. Prevention of relapses and disability by interferon-betala subcutaneously in multiple sclerosis. Ann Neurol 1999;46:197-206.

35. Ge Y, Grossman RI, Udupa JK, et al. Glatiramer acetate (Copaxone) treatment in relapsing-remitting MS: quantitative MR assessment. Neurology 2000;54:813-7.

36. Ebers G. Randomised double-blind placebo-controlled study of interferon beta-1a in relapsing/remitting multiple sclerosis. PRISMS (Prevention of Relapses and Disability by Interferon beta-1a Subcutaneously in Multiple Sclerosis) Study Group. Lancet 1998;352:1498-504

37. Jacobs LD, Cookfair DL, Rudick RA, et al. Intramuscular interferon beta-1a for disease progression in relapsing multiple sclerosis. The Multiple Sclerosis Collaborative Research Group (MSCRG). Ann Neurol 1996;39:285-94.
38. Rudick RA, Goodkin DE, Jacobs LD, et al. Impact of interferon beta-1a on neurologic disability in relapsing multiple sclerosis. The Multiple Sclerosis Collaborative Research Group (MSCRG). Neurology 1997;49:358-63.

39. Hughes D. PRISMS-4: Long-term efficacy of interferon-beta-1a in relapsing MS. Neurology 2001;56:1628-36.

40. Panitch H, Goodin DS, Francis G, et al. Randomized, comparative study of interferon beta-1a treatment regimens in MS: The EVIDENCE Trial. Neurology 2002;59:1496-506.

41. Durelli L, Verdun E, Barbero P, et al. Every-other-day interferon beta-1b versus once-weekly interferon beta-1a for multiple sclerosis: results of a 2-year prospective randomised multicentre study (INCOMIN). Lancet 2002;359:1453-60.

42. Barbero P, Bergui M, Versino E, et al. Every-other-day interferon beta-1b versus once-weekly interferon beta-1a for multiple sclerosis (INCOMIN Trial) II: analysis of MRI responses to treatment and correlation with Nab. Mult Scler 2006;12:72-6.

43. Vollmer TL, Phillips JT, Goodman AD, et al. An open-label safety and drug interaction study of natalizumab (Antegren) in combination with interferon-beta (Avonex) in patients with multiple sclerosis. Mult Scler 2004;10:511-20.

44. Rudick RA, Stuart WH, Calabresi PA, et al. Natalizumab plus interferon beta-1a for relapsing multiple sclerosis. N Engl J Med 2006;354:911-23

45. Polman CH, O'Connor PW, Havrdova E, et al. A randomized, placebo-controlled trial of natalizumab for relapsing multiple sclerosis. N Engl J Med 2006;354:899-910.

46. Klawiter EC, Cross AH, Naismith RT. The present efficacy of multiple sclerosis therapeutics: Is the new $66 \%$ just the old $33 \%$ ? Neurology 2009;73:984-90.

47. Freedman MS, Hughes B, Mikol DD, et al. Efficacy of diseasemodifying therapies in relapsing remitting multiple sclerosis: a systematic comparison. Eur Neurol 2008;60:1-11.

48. Kappos L, SPMS ESGoIa. Placebo-controlled multicentre randomised trial of interferon beta- $1 \mathrm{~b}$ in treatment of secondary progressive multiple sclerosis. European Study Group on interferon beta-1b in secondary progressive MS. Lancet 1998;352:1491-7.

49. Miller DH, Molyneux PD, Barker GJ, MacManus DG, Moseley IF, Wagner K. Effect of interferon-betalb on magnetic resonance imaging outcomes in secondary progressive multiple sclerosis: results of a European multicenter, randomized, double-blind, placebo-controlled trial. European Study Group on Interferon-betalb in secondary progressive multiple sclerosis. Ann Neurol 1999;46:850-9.

50. Panitch H, Miller A, Paty D, Weinshenker B. Interferon beta- $1 \mathrm{~b}$ in secondary progressive MS: results from a 3-year controlled study. Neurology 2004;63:1788-95.

51. Kappos L, Weinshenker B, Pozzilli C, et al. Interferon beta-1b in secondary progressive MS: a combined analysis of the two trials. Neurology 2004;63:1779-87.

52. McFarland HF. Alemtuzumab versus interferon beta-1a: implications for pathology and trial design. Lancet Neurol 2009;8: $26-8$.

53. Fisher E, Rudick RA, Simon JH, et al. Eight-year follow-up study of brain atrophy in patients with MS. Neurology 2002;59:1412-20.

54. Barkhof F. MRI in multiple sclerosis: correlation with expanded disability status scale (EDSS). Mult Scler 1999;5:283-6.

55. van Walderveen MA, Kamphorst W, Scheltens P, et al. Histopathologic correlate of hypointense lesions on T1-weighted spin-echo MRI in multiple sclerosis. Neurology 1998;50:1282-8.

56. Truyen $\mathrm{L}$, van Waesberghe $\mathrm{JH}$, van Walderveen $\mathrm{MA}$, et al Accumulation of hypointense lesions ("black holes") on T1 spinecho MRI correlates with disease progression in multiple sclerosis Neurology 1996;47:1469-76.

57. Naismith RT, Xu J, Tutlam NT, et al. Increased diffusivity in acute multiple sclerosis lesions predicts risk of black hole. Neurology 2010;74:1694-701

58. Bagnato F, Jeffries N, Richert ND, et al. Evolution of T1 black holes in patients with multiple sclerosis imaged monthly for 4 years. Brain 2003;126:1782-9.

59. Bakshi R, Neema M, Healy BC, et al. Predicting clinical progression in multiple sclerosis with the magnetic resonance disease severity scale. Arch Neurol 2008;65:1449-53. 
60. Barkhof F, Calabresi PA, Miller DH, Reingold SC. Imaging outcomes for neuroprotection and repair in multiple sclerosis trials. Nat Rev Neurol 2009;5:256-66.

61. Filippi M, Rovaris M, Rocca MA, Sormani MP, Wolinsky JS, Comi G. Glatiramer acetate reduces the proportion of new MS lesions evolving into "black holes". Neurology 2001;57:731-3.

62. Richert ND. Glatiramer acetate reduces the proportion of new MS lesions evolving into "black holes". Neurology 2002;58:14401441; author reply $1-2$.

63. Barkhof F, van Waesberghe JH, Filippi M, et al. T(1) hypointense lesions in secondary progressive multiple sclerosis: effect of interferon beta-1b treatment. Brain 2001;124:1396-402.

64. Bagnato F, Gupta S, Richert ND, et al. Effects of interferon beta-1b on black holes in multiple sclerosis over a 6-year period with monthly evaluations. Arch Neurol 2005;62:1684-8.

65. Gasperini C, Pozzilli C, Bastianello S, et al. Interferon-beta-1a in relapsing-remitting multiple sclerosis: effect on hypointense lesion volume on T1 weighted images. J Neurol Neurosurg Psychiatry 1999;67:579-84.

66. Cadavid D, Cheriyan J, Skurnick J, Lincoln JA, Wolansky LJ, Cook SD. New acute and chronic black holes in patients with multiple sclerosis randomised to interferon beta- $1 \mathrm{~b}$ or glatiramer acetate. J Neurol Neurosurg Psychiatry 2009;80:1337-43.

67. van den Elskamp IJ, Lembcke J, Dattola V, et al. Persistent T1 hypointensity as an MRI marker for treatment efficacy in multiple sclerosis. Mult Scler 2008;14:764-9.

68. Simon JH, Jacobs LD, Campion MK, et al. A longitudinal study of brain atrophy in relapsing multiple sclerosis. The Multiple Sclerosis Collaborative Research Group (MSCRG). Neurology 1999;53:13948.

69. Rudick RA, Fisher E, Lee JC, Simon J, Jacobs L. Use of the brain parenchymal fraction to measure whole brain atrophy in relapsingremitting MS. Multiple Sclerosis Collaborative Research Group. Neurology 1999;53:1698-704.

70. Zivadinov R, Reder AT, Filippi M, et al. Mechanisms of action of disease-modifying agents and brain volume changes in multiple sclerosis. Neurology 2008;71:136-44.

71. De Stefano N, Giorgio A, Battaglini M, et al. Assessing brain atrophy rates in a large population of untreated multiple sclerosis subtypes. Neurology 2010;74:1868-76.

72. Fisher E, Rudick RA, Cutter G, et al. Relationship between brain atrophy and disability: an 8-year follow-up study of multiple sclerosis patients. Mult Scler 2000;6:373-7.

73. Rudick RA, Fisher E, Lee JC, Duda JT, Simon J. Brain atrophy in relapsing multiple sclerosis: relationship to relapses, EDSS, and treatment with interferon beta-1a. Mult Scler 2000;6:365-72.

74. Frank JA, Richert $\mathrm{N}$, Bash $\mathrm{C}$, et al. Interferon-beta-1b slows progression of atrophy in RRMS: Three-year follow-up in NAband NAb + patients. Neurology 2004;62:719-25.

75. Hardmeier M, Wagenpfeil S, Freitag P, et al. Rate of brain atrophy in relapsing MS decreases during treatment with IFNbeta-1a. Neurology 2005;64:236-40.

76. Molyneux PD, Kappos L, Polman C, et al. The effect of interferon beta-1b treatment on MRI measures of cerebral atrophy in secondary progressive multiple sclerosis. Brain 2000:2256-63.

77. Rovaris M, Comi G, Rocca MA, Wolinsky JS, Filippi M. Shortterm brain volume change in relapsing-remitting multiple sclerosis: effect of glatiramer acetate and implications. Brain 2001;124: $1803-12$.

78. Sormani MP, Rovaris M, Valsasina P, Wolinsky JS, Comi G, Filippi M. Measurement error of two different techniques for brain atrophy assessment in multiple sclerosis. Neurology 2004;62:1432-4.

79. Bendfeldt K, Blumhagen JO, Egger H, et al. Spatiotemporal distribution pattern of white matter lesion volumes and their association with regional grey matter volume reductions in relapsing-remitting multiple sclerosis. Hum Brain Mapp 2010;31:1542-55.

80. Zivadinov R, Locatelli L, Cookfair D, et al. Interferon beta-1a slows progression of brain atrophy in relapsing-remitting multiple sclerosis predominantly by reducing gray matter atrophy. Mult Scler 2007;13:490-501.

81. Bendfeldt K, Egger H, Nichols TE, et al. Effect of immunomodulatory medication on regional gray matter loss in relapsing-remitting multiple sclerosis-a longitudinal MRI study. Brain Res 2010;1325:174-82.

82. Bo L, Vedeler CA, Nyland HI, Trapp BD, Mork SJ. Subpial demyelination in the cerebral cortex of multiple sclerosis patients. J Neuropathol Exp Neurol 2003;62:723-32.

83. Bagnato F, Butman JA, Gupta S, et al. In vivo detection of cortical plaques by MR imaging in patients with multiple sclerosis. AJNR Am J Neuroradiol 2006;27:2161-7.

84. Kutzelnigg A, Lucchinetti CF, Stadelmann C, et al. Cortical demyelination and diffuse white matter injury in multiple sclerosis. Brain 2005; 128:2705-12.

85. Magliozzi R, Howell O, Vora A, et al. Meningeal B-cell follicles in secondary progressive multiple sclerosis associate with early onset of disease and severe cortical pathology. Brain 2007;130:1089-104.

86. Geurts JJ, Bo L, Pouwels PJ, Castelijns JA, Polman CH, Barkhof F. Cortical lesions in multiple sclerosis: combined postmortem MR imaging and histopathology. AJNR Am J Neuroradiol 2005;26:572-7.

87. Cifelli A, Arridge M, Jezzard P, Esiri MM, Palace J, Matthews PM Thalamic neurodegeneration in multiple sclerosis. Ann Neurol 2002;52:650-3

88. Wylezinska M, Cifelli A, Jezzard P, Palace J, Alecci M, Matthews PM. Thalamic neurodegeneration in relapsing-remitting multiple sclerosis. Neurology 2003;60:1949-54.

89. Houtchens MK, Benedict RH, Killiany R, et al. Thalamic atrophy and cognition in multiple sclerosis. Neurology 2007;69:1213-23.

90. Calabrese M, Rinaldi F, Grossi P, et al. Basal ganglia and frontal/ parietal cortical atrophy is associated with fatigue in relapsingremitting multiple sclerosis. Mult Scler 2010;16:1220-8.

91. Sicotte NL, Kern KC, Giesser BS, et al. Regional hippocampal atrophy in multiple sclerosis. Brain 2008;131:1134-41.

92. Papadopoulos D, Dukes S, Patel R, Nicholas R, Vora A, Reynolds R. Substantial archaeocortical atrophy and neuronal loss in multiple sclerosis. Brain Pathol 2009;19:238-53.

93. Geurts JJ, Bo L, Roosendaal SD, et al. Extensive hippocampal demyelination in multiple sclerosis. J Neuropathol Exp Neurol 2007;66:819-27.

94. Gold SM, Kern KC, O'Connor MF, et al. Smaller cornu ammonis 2-3/dentate gyrus volumes and elevated cortisol in multiple sclerosis patients with depressive symptoms. Biol Psychiatry 2010;68:553-9.

95. Anderson V, Fisniku L, Khaleeli Z, et al. Hippocampal atrophy in relapsing-remitting and primary progressive MS: a comparative study. Mult Scler 2010;16:1083-90.

96. Freedman MS, Forrestal FG. Canadian treatment optimization recommendations (TOR) as a predictor of disease breakthrough in patients with multiple sclerosis treated with interferon beta-1a: analysis of the PRISMS study. Mult Scler 2008;14:1234-41.

97. Gauthier SA, Glanz BI, Mandel M, et al. Incidence and factors associated with treatment failure in the CLIMB multiple sclerosis cohort study. J Neurol Sci 2009;284:116-9.

98. Axtell RC, de Jong BA, Boniface K, et al. T helper type 1 and 17 cells determine efficacy of interferon-beta in multiple sclerosis and experimental encephalomyelitis. Nat Med 2010;16:406-12.

99. Hesse D, Krakauer M, Lund H, et al. Breakthrough disease during interferon-[beta] therapy in MS: No signs of impaired biologic response. Neurology 2010;74:1455-62.

100. Mainero C, Benner T, Radding A, et al. In vivo imaging of cortical pathology in multiple sclerosis using ultra-high field MRI. Neurology 2009;73:941-8.

101. Calabrese M, Battaglini M, Giorgio A, et al. Imaging distribution and frequency of cortical lesions in patients with multiple sclerosis. Neurology 2010;75:1234-40.

102. Dwyer M, Bergsland N, Hussein S, Durfee J, Wack D, Zivadinov R. A sensitive, noise-resistant method for identifying focal demyelination and remyelination in patients with multiple sclerosis via voxel-wise changes in magnetization transfer ratio. J Neurol Sci 2009;282:86-95.

103. Sajja BR, Wolinsky JS, Narayana PA. Proton magnetic resonance spectroscopy in multiple sclerosis. Neuroimaging Clin N Am 2009;19:45-58.

104. Srinivasan R, Sailasuta N, Hurd R, Nelson S, Pelletier D. Evidence of elevated glutamate in multiple sclerosis using 
magnetic resonance spectroscopy at 3 T. Brain 2005;128:101625.

105. Fink F, Eling P, Rischkau E, et al. The association between California Verbal Learning Test performance and fibre impairment in multiple sclerosis: evidence from diffusion tensor imaging. Mult Scler 2010;16:332-41.

106. Dasenbrock HH, Smith SA, Ozturk A, Farrell SK, Calabresi PA, Reich DS. Diffusion Tensor Imaging of the Optic Tracts in Multiple Sclerosis: Association with Retinal Thinning and Visual Disability. J Neuroimaging 2010 March 17 [Epub ahead of print]

107. Ceccarelli A, Rocca MA, Valsasina P, et al. Structural and functional magnetic resonance imaging correlates of motor network dysfunction in primary progressive multiple sclerosis. Eur J Neurosci 2010;31:1273-80.

108. Deoni SC, Rutt BK, Arun T, Pierpaoli C, Jones DK. Gleaning multicomponent $\mathrm{T} 1$ and $\mathrm{T} 2$ information from steady-state imaging data. Magn Reson Med 2008;60:1372-87.
109. Laule C, Leung E, Lis DK, et al. Myelin water imaging in multiple sclerosis: quantitative correlations with histopathology. Mult Scler 2006;12:747-53.

110. Haacke EM, Makki M, Ge Y, et al. Characterizing iron deposition in multiple sclerosis lesions using susceptibility weighted imaging. J Magn Reson Imaging 2009;29:537-44.

111. Matthews PM, Comley R. Advances in the molecular imaging of multiple sclerosis. Expert Rev Clin Immunol 2009;5:765-77.

112. Inglese M, Madelin G, Oesingmann N, et al. Brain tissue sodium concentration in multiple sclerosis: a sodium imaging study at 3 tesla. Brain 2010;133:847-57.

113. Pagani E, Hirsch JG, Pouwels PJ, et al. Intercenter differences in diffusion tensor MRI acquisition. J Magn Reson Imaging 2010;31:1458-68.

114. De Stefano N, Filippi M, Miller D, et al. Guidelines for using proton MR spectroscopy in multicenter clinical MS studies. Neurology 2007;69:1942-52. 